\title{
Reflections from Teaching Basic Adult Literacy
}

Inga Einarson, The Hospital for Sick Children

Christine Miller, Georgia State University

Devi Rodgerson, The Hospital for Sick Children

Lea Lacerenza, The Hospital for Sick Children

Maureen W. Lovett, The Hospital for Sick Children and University of Toronto

Daphne Greenberg, Georgia State University

Acknowledgment: The information reported here is supported by the Institute of Education Sciences, U.S. Department of Education, through Grant R305C120001 (Georgia State University). The opinions expressed are those of the authors and do not represent views of the Institute or the U.S. Department of Education.

\begin{abstract}
Teaching reading to adults who struggle with literacy learning is a difficult task, and there is a paucity of evidence-based programming designed especially for them. Three research teachers describe their experiences while teaching an evidence-based reading program to adult literacy students. This article provides an overview of the program content delivered to adult learners, an account of teachers' experiences teaching this program, a description of the learners' responses to the program, and a portrayal of what the learners' responses revealed about their educational needs.
\end{abstract}

Keywords: reading intervention, adult learners, evidence-based reading programs

Teaching reading to adults who struggle with literacy learning is a difficult task, and there is a paucity of evidence-based programming designed especially for them. Research comparing the results of one instructional approach to another, or to a control condition has yet to identify the benefits of any one approach over any other. This lack of evidence is further exacerbated by not knowing enough about their greatest learning challenges.
This article describes the experiences of three research teachers (Inga Einarson, Christine Miller, and Devi Rodgerson) working for an adult literacy research and development center (csal.gsu.edu). The overall center objectives are to better understand the reading strengths and weaknesses of adult literacy learners and to develop and test an instructional program to help them acquire foundational literacy skills and improve their reading. Our goals for this paper are to provide an overview of the 
program content delivered in our classes, share our experiences teaching this program, describe the learners' responses to the program, and to consider what the learners' responses reveal about their educational needs.

Our classes were held in established adult literacy program sites in Metro Atlanta and in the Greater Toronto Area. The intervention offered approximately 100 hours of reading instruction. Classes typically met twice a week, for approximately 3 hours. Class size varied from 6-16 learners. Typical of most adult literacy programs (Greenberg, 2008), learners varied in gender, age, race, educational history, and native language status. They read at a 3.0 through 7.9 grade level equivalency (determined by their adult literacy programs).

We delivered a hybrid curriculum. The three teacher-led components included a decoding and spelling strategy program (Adult PHAST), word study (Vocabulary Bridge), and a reading comprehension program (Adult PACES).

These components were modeled on research interventions developed for children and adolescents and evaluated by Lovett and colleagues (Lovett et al., 2000; Lovett et al., 2008; Lovett et al., 2012; Lovett et al., 2014; Lovett et al., 2017; Morris et al., 2012). The classes also included AutoTutor, a computer-based intelligent tutoring system, developed by Graesser and colleagues (Graesser, 2011; Graesser \& McNamara, 2010) designed to further consolidate learning of the Adult PACES comprehension strategies and content. Independent Reading allowed learners to practice the strategies taught with self-selected texts. We focus attention here on the Adult PHAST instruction, a class component typically taking approximately 45 minutes.

\section{The Adult PHAST Program}

Adult PHAST consists of 30 scripted lessons that teach three metacognitive decoding and spelling strategies: Sounding Out, Peeling Off, and Vowel Alert. Metacognitive strategies are important to all aspects of reading development (Liberman \& Shankweiler, 1991; Perfetti et al., 2005). Strategy acquisition, application, and self-monitoring are essential to learning and are crucial to positive remedial outcomes. The three decoding and spelling strategies, as well as their prerequisite skills, are taught sequentially, each skill building on the previous, and practiced cumulatively. Once these strategies are acquired, learners are taught the Game Plan, a metacognitive framework designed to help learners select, apply, monitor, and evaluate their application of the strategies. Daily worksheets and text reading provide opportunities to apply the strategies utilizing the Game Plan. Lessons are scripted to allow consistent implementation of all aspects of the instructional design.

The first strategy introduced is the Sounding Out Strategy. First, learners are taught the correct pronunciation and identification of the English phonemes. Although all of the sounds are introduced by the $15^{\text {th }}$ lesson, they are practiced throughout the intervention to facilitate consolidation and ease of retrieval. Learners are also taught how to blend and segment individual sounds in monosyllabic (e.g., $\mathrm{r} / \mathrm{a} / \mathrm{m} / \mathrm{p}$ ) and syllables in multisyllabic (e.g., sub/stance) words. All skills are presented and practiced orally before moving to print representations.

As the phonological skills progress, the Peeling Off Strategy is introduced. Learners are taught that many long words consist of affixes and roots. They learn to identify, pronounce, and segment prefixes (e.g., pre-, un-, mis-) and suffixes (e.g., -ing, -less, -tion) from the root of a word, thereby 
facilitating the process of reading and spelling longer multisyllabic words. Learners practice the Peeling Off Strategy on worksheets and while reading text.

The Vowel Alert Strategy is the third and final strategy introduced. This strategy focuses on vowels, especially vowel teams, and is introduced halfway through the lessons. Learners are taught to apply a flexible approach to decoding and spelling words containing individual vowels and vowel teams; they try the most frequently occurring pronunciation first, the next most frequent second, etc. For example, when encountering the unknown word scowl, the learner would be taught to recognize that ow has two pronunciations (ow as in glow and ow as in cow) and taught to be flexible when reading the word scowl.

Once learners have practiced the three strategies, the Game Plan is introduced. The Game Plan is a metacognitive organizational structure designed to help learners select strategies based on clues in a word, apply the strategies correctly, monitor application of the strategies, and evaluate whether they were able to successfully read or spell a word. When unsuccessful, they are taught to select and apply another strategy. Learners are given many opportunities to practice the Game Plan, using a variety of activities and texts, and are praised for being flexible and trying a second strategy if the initial strategy did not reveal the unknown word.

\section{The Experience of Teaching the Adult PHAST Program}

As teachers, we participated in considerable professional development before we began to implement the teacher-led components. The intervention developers conducted intensive threeday workshops, and continued mentoring was provided for over a year. Our mentors periodically observed our classes and provided constructive feedback and ongoing support. Regular phone and videoconference meetings enabled us to discuss our experiences and receive additional support.

Delivering a scripted program was new to all of us, but with practice, we became more confident and soon saw its benefits as it became more internalized and natural. Scripted lessons ensured that delivery was fast-paced, and strategies were presented consistently. The scripted lessons also ensured that the learners got the maximum benefit from the well-documented research upon which the program is based.

Teacher modeling of each of the skills and strategies supported correct use of strategy dialogues and applications. Adult PHAST also called for learners to respond on cue as they practiced the preskills for the strategies. Learner responses, especially with skill practice, were often voiced in unison. This has many benefits; it ensures that learners initiate their own response, helps the teacher hear if learners are articulating a sound incorrectly, allows for group corrective feedback, and maintains a fast lesson pace. Some of the more reluctant learners participated more and showed willingness to respond when prompted this way. We also found that the repetitive dialogue along with the scaffolded structure of the program proved beneficial to the learners and supported retention of newly learned material.

In all of our classes, there were learners with cognitive limitations, health issues, absences, learning disabilities, and those who spoke English as a second language making differentiation in our class sessions important. Yet, due to time constraints, it was sometimes difficult to implement. However, we were able to provide differentiation daily when learners worked 
individually on the Adult PHAST worksheets. We also had the flexibility to access simpler or more complex words for spelling dictation. For more struggling learners, we directed them to easier tasks and expected them to complete less than more capable learners. The built-in practice and cumulative review were helpful in keeping learners on task and supported learning.

\section{Feedback from the Adult Learners}

The majority of learners demonstrated a high level of engagement and motivation in the program. Their goals, shared during their first week of class, included being able to read to their children or grandchildren, get their high school equivalency diplomas, enroll in post-secondary education, meet educational requirements for specific careers, and be able to read medical information when visiting the doctor. We believe that the motivation to accomplish these personal goals, helped create a sense of community, fostering nurturing, supportive attitudes towards each other. Learners regularly encouraged one another with supportive comments. We also found that community building helped learners, who may have otherwise felt reluctant to articulate and blend sounds out loud or take turns applying the strategies in front of their peers, feel more comfortable doing so.

Although most learners were enthusiastic from the start, there were a few who felt that the program's initial focus on foundational phonological skills was too simplistic and considered dropping the class. However, after the first few classes, they noticed that their learning needs were being met, and Adult PHAST became their favorite part of class. One ESL learner, having had post-secondary education in her native country, shared that she found the Adult PHAST component helped her decoding accuracy and reading fluency. Another learner read monosyllabic words easily but found it very difficult to read multisyllabic words fluently. She said the Sounding Out and Peeling Off Strategies were particularly beneficial. Many learners with lower reading capabilities shared that all aspects of Adult PHAST were helpful. Others commented that they had never been taught how to read this way and expressed appreciation for this approach. This has helped us reflect on how critical it is to teach basic, foundational skills to struggling readers so that they are better equipped for higher-level skill building.

We found that when classes ended, however, some learners continued to struggle with certain Adult PHAST skills. Recalling all of the affixes, single vowel, and vowel team sounds, as well as applying the Game Plan independently were some of the challenges experienced. There are many possible explanations for this, such as absenteeism and the program's time limitations. Likely, learners were unable to consolidate the over 100 affixes taught between Lessons 10-30 within the time available.

The Vowel Alert Strategy was also challenging. Although learners could recognize the importance of being flexible with vowel and vowel team sounds, many found it difficult to apply this strategy independently. Finally, many learners found it difficult to apply the Game Plan. Due to the amount of content taught, further practice with the skills and strategies and more time for consolidation would have been beneficial. In fact, after the intervention classes ended, many learners wanted to continue working on the Adult PHAST skills and strategies. In some sites, review classes were offered and proved very popular. Learners were also eager to take home copies of the support materials used in class, for further practice.

Despite the challenges, by the end of the program, most learners demonstrated that they were often able to apply the Adult PHAST strategies 
when decoding or spelling new words. Learners showed increased reading and spelling abilities and reading confidence. This was apparent as learners shared that they were reading more, helping their children with homework more, and teaching what they had learned to others. One learner shared that, upon arriving in the airport after an international flight, he was able to read and accurately fill out a customs declaration card, something he previously needed help with. Another learner happily reported that she had read aloud and helped write signs at work; these were activities that she never volunteered to do prior to attending class. A math teacher who taught some of our learners noted learners' improved ability to read math problems.

\section{Conclusions}

Although no generalizable claims can be drawn from our experiences, we found that delivering the Adult PHAST Program was an enlightening experience. The professional development we received as a feature of the Adult PHAST Program was highly beneficial. This training ensured that we had the required knowledge and skills to implement the program effectively. Furthermore, the mentoring support we received while teaching also provided us with the additional guidance we needed as we progressed through the lessons.

We learned how critical it is to teach basic foundational reading skills and how eager most adults who struggle with literacy are to receive this instruction. Even our higher-level learners (reading at $6^{\text {th }}-7^{\text {th }}$ grade equivalency levels) benefitted because they sometimes had phonological knowledge gaps. We also learned how beneficial it is to carefully sequence the skills and strategies taught so that learners can retain and build on what they learn at a pace suitable to their needs.

Despite the learners' heterogeneity, their motivation was, generally, very high. They were hungry for more instruction on sounds, affixes, syllables, word meanings, and eager to participate in review classes when available. It is important to address these needs and fill learning gaps, and it is never too late to improve on these building blocks of literacy and fluent reading comprehension. 


\section{References}

Graesser, A. C. (2011). Learning, thinking, and emoting with discourse technologies. American Psychologist, 66, 743-757.

Graesser, A. C., \& McNamara, D. (2010). Self-regulated learning in learning environments with pedagogical agents that interact in natural language. Educational Psychologist(4), 234-244.

Greenberg, D. (2008). The challenges facing adult literacy programs. Community Literacy Journal, 3, 39-54.

Liberman, I.Y., \& Shankweiler, D. (1991) Phonology and beginning reading: A tutorial. In L. Rieben \& C.A. Perfetti (Eds.), Learning to read: Basic research and its implications (pp. 3-17). Erlbaum.

Lovett, M. W., Frijters, J. C., Wolf, M. A., Steinbach, K. A., Sevcik, R. A., \& Morris, R. D. (2017). Early intervention for children at risk for reading disabilities: The impact of grade at intervention and individual differences on intervention outcomes. Journal of Educational Psychology, 109(7), 889-914.

Lovett, M. W., Lacerenza, L., \& Borden, S. L. (2000). Putting struggling readers on the PHAST track: A program to integrate phonological and strategy-based remedial reading instruction and maximize outcomes. Journal of Learning Disabilities, 33(5), 458-476.
Lovett, M. W., Lacerenza, L., De Palma, M., Benson, N. J., Steinbach, K. A., \& Frijters, J. C. (2008). Preparing teachers to remediate reading disabilities in high school: What is needed for effective professional development? Teaching and Teacher Education, 24(4), 1083-1097.

Lovett, M. W., Lacerenza, L., De Palma, M., \& Frijters, J. C. (2012). Evaluating the efficacy of remediation for struggling readers in high school. Journal of Learning Disabilities, 45(2), 151-169.

Lovett, M. W., Lacerenza, L., Steinbach, K. A., \& De Palma, M. (2014). Development and roll-out of a researchbased intervention program for children with reading disabilities. Perspectives on Language and Literacy, 40, 21-31.

Morris, R. D., Lovett, M. W., Wolf, M. A., Sevcik, R. A., Steinbach, K. A., Frijters, J. C., \& Shapiro, M. (2012). Multiple-component remediation for developmental reading disabilities: IQ, socioeconomic status, and race as factors in remedial outcome. Journal of Learning Disabilities, 45(2), 99-127.

Perfetti, C.A., Landi, N., Oakhill, J., \& Snowling, M.J. (2005). The acquisiton of reading comprehension skill. In C.Hulme (Ed.), The science of reading: A handbook (pp.117-147). Blackwell. 